\title{
Organizational factors promoting the uptake of informal learning within NIEs: a dual case study of a consulting firm and legal / health professionals
}

\author{
Myriam Benabid \\ CERIIM - Excelia Business School \\ benabidm@excelia-group.com
}

\begin{abstract}
The effectiveness of corporate training continues to be questioned, despite its ongoing growth. Most learning time is spent in informal situations, triggered by situational needs and Nomadic Information Environments (NIEs). This is especially the case for knowledge-intensive workers who seek out knowledge that is less codified, but which is harder to identify exante. This article explores the connection between selflearning within NIEs and its context. Our theoretical framework is based on the work around informal learning, suggesting factors leading to the uptake of such practices. Through inductive reasoning, we applied a qualitative protocol for data collection in the context of two case studies representing knowledgeintensive workers. 32 interviews were conducted using a semi-directive approach. Triangulation was carried out analyzing 200 documents and tools, and 3 teams were shadowed and observed. We highlight 11 organizational factors (professional, managerial and technological). Our work updates the informal learning factors within the specific context of NIEs. By identifying these factors, we also recognize the need for organizations to facilitate access to suitable, efficient and high-quality self-learning options.
\end{abstract}

\section{Introduction}

In France, according to a study by HRM Digital $\mathrm{Lab}^{1}$, more than 6 out of 10 professionals declare to be self-taught via digital technology. More broadly, other studies unveil "The Great Training Robbery" [1], showing that about $90 \%$ of training expenses are not used by professionals. Yet in 2012, the United States, for example, spent $\$ 162$ billion on business development. In this article we aim to better understand the factors promoting the uptake of informal learning within NIEs. This will allow to provide insight into the reasons for these training expenses not used by professionals and to optimize the training costs of the companies.

Does this mean that professionals no longer wish to "train" or develop their skills? No, quite the contrary! However, the modes of learning chosen by employees have changed. The less well-adapted learning solutions prescribed by organizations are now set aside as day-today working life begins to favor rational, measured learning resulting from informal situations. Digitalization makes this more challenging at several levels. Learning and skills development methods are changing with an increase in the importance of communities of practice, open-source projects, and digital self-learning methods (ability to obtain information on the Internet, to consult video tutorials, to follow MOOCs, etc.). Moreover, when work can be done anywhere, commitment to the company can no longer be built through physical and informal meetings in the workplace. However, commitment can be built through Nomadic Information Environments (NIE)s [2]. The exchange of information and tacit knowledge therefore becomes complicated. The above gives just some examples of the factors involved in informal learning through NIEs. These informal learning situations, defined as "a category that includes incidental learning, may occur in institutions, but it is not typically classroom- based or highly structured, and control of learning rests primarily in the hands of the learner.",[3] originated well before the rise of the Numerical Revolution.

In order to update the list of informal learning factors, our research looks at the current contexts of organizations within NIEs. NIEs are defined as "a heterogeneous assemblage of interconnected technological, and social, and organizational elements that enable the physical and social mobility of computing and communication services between organizational actors both within and across

\footnotetext{
${ }^{1}$ Study carried out among 1004 employees from all sectors of activity. $61 \%$ of respondents report learning independently through digital tools.
} 
organizational borders" (p.377) [4]. NIEs are anchored in the digital universe of web 1.0 (static information), web 2.0 (social), web 3.0 (semantics), and now/soon web 4.0 (intelligent). The training sector has flourished, and formal learning situations are now potentially full of pedagogical innovations. The open and free dimension is also risky and does not guarantee finding the most effective or reliable learning solution. NIEs?

So, why do knowledge workers self-learn within

To understand this, our research examines the field of knowledge workers through a dual case study. We demonstrate that informal learning within NIEs is associated with organizational factors, including professional, managerial and technological environments. The characteristics of these new modes and organizational contexts leads to new, previously unidentified learning factors, such as the "professional" factor, which includes: the pace, the quantity and the nature of work, performance requirements, and the fragmentation of the physical and time spaces in which knowledge workers carry out their work. In the eyes of learners, informal learning within NIEs seems to be more "effective"; their daily working life is demanding, fast-paced and impacted by rapid changes in business and markets. "There are a lot of drugs coming out every day and it's very important to always be up to date." (Iw22_Pharmacist).

Our paper is organized as follows. Firstly, we introduce the literature on factors of informal learning within NIEs. We then describe our research design, followed by a presentation of our results. Finally, the implications of our research are discussed.

\section{A panorama of informal learning factors}

The concept of informal learning within NIEs is emerging in research on informal learning and remains unstructured. However, authors on informal learning had already identified the emergence of digital technologies in informal practices [5]. Therefore, the factors mobilized are those related to informal learning, with the reference field associated with technological factors proposing factors that are specific to uptake within NIEs.

\subsection{Professional factors}

The professional environment is the work environment defined by the function occupied by employees. Firstly, our learning develops according to the demands of our environment [6]. Applied to the context of work, professional learning develops according to routines, daily needs and professions as well as daily breaks with habits. The latter creates a barrier to progress for individuals and thus their ability to acquire missing skills. When individuals have control over their work, learning increases. A "greater control or task autonomy may allow individuals to create learning opportunities" [7]. Secondly, the position occupied will determine the people with whom employees interact on a daily basis, especially in production situations [8]. These exchanges will feed knowledge, soft skills (self-confidence, etc.) and knowhow (presentations, running meetings). The functional environment therefore plays a key role in employee learning opportunities. We will see that the technological environment also presents other opportunities for access to learning. We will also study the vectors of exchange (internal and external social networks, among others) and access to rich digital resources.

\subsection{Managerial factors}

2.2.1 Social support mechanisms. The roles of managers influencing the learning of their teams falls into three categories: interpersonal, information and decision-making roles [9].

Learning styles are shaped both by the surrounding world and the learner's experience [10]. As such, the involvement of the proximity manager in HRM practices is now very real in organizations [11]. These organizational players must be considered as the "strong link" in the deployment of the HR policy. They are the silversmiths of the implementation of HR tools that allow the HR process to unfold, through its decision-maker and prescriber functions, but also as an informant and advisor [12].

More broadly, these could include variables such as an organizational learning climate, discussions of learning opportunities associated with assignments or projects, the use of team debriefs that could encourage reflective behaviors, and leaders who think aloud about their experiences to encourage others to reflect on their own. [13]. The manager determines the level of skills and responsibilities to be achieved by coordinators, and the individual activities required for a collective result [14]. Managers also play an advisory role when they have gained the confidence of their teams [15]. This dimension is more relevant to the relationship and leadership aspect of the manager, intrinsically linked to the motivations of the members of their teams thanks to their encouragement, the values communicated, a shared vision and the projects developed by the 
organization. Applied to learning, this role can be found at two different levels: 1) taking responsibility is a learning factor that depends on the involvement of the employee in the discovery of qualitatively and quantitatively different assignments. The development of learning is born in this case also from the fear of failure in these new responsibilities. 2) The orientation of learning behaviors. The manager can provide advice on resources to be consulted for learning: contact persons, articles and books to read or conference events to attend. They can also implement projects in collaboration with experts to enable a transmission of skills. Finally, individuals learn indirectly by observing the behavior of others and the results that arise from this behavior [16].

2.2.2 Corporate Culture. Corporate culture is the context, values and spirit in which teams work together. Informal learning situations occur within a voluntary, flexible, open, and agile enterprise [17]. Indeed, the company has to promote spaces of socialization, exchanges and transversality as well as proposing a flexible corporate culture federated around teams [18]. The organizational climate, support and encouragement, learning opportunities and the relation to time play a determining role in the opportunities for access to informal learning situations for employees [13]. In fact, it depends on the organizational structures (composition, objectives, missions and budgets), thus offering learning opportunities to collaborators. These decisions can lead to a more organizational and hierarchical flexibility: reducing the size of multi-skilled teams, opening up to experts and other companies, cross- cutting between departments, or rotating staff between units. "A malleable environment enables a proactive employee to generate learning opportunities" [7]. The structure has many levers as a facilitator or obstructer of informal learning [19]. Decisions facilitate or constrain contacts between individuals, promote the sharing and dissemination of knowledge, require the updating of skills and thus create learning opportunities. The organization can encourage peers to work and learn collaboratively [20]. Becoming a learning organization [21] or promoting organizational learning involves a set of triggers and learning processes for staff (socialization, organizational innovation, coding). The evolution of the learning process is optimized when the common data is minimal. The relationship to time also influences informal learning [13]. "In learning organizations, individuals continually improve their ability to create the desired results, new ways of thinking arise and develop continually, the collective vision provides a significant margin of freedom, and individuals continually learn how to learn better together." [22]

\subsection{Technological factors}

"There is no social that is material and no material that is not social." (Orlikowski, 2007) [23].

The technological environment is the capital of technological and digital tools made available to employees. The structure offers its employees new practices of learning, including through the work environment and tools it provides, where self- organized learning processes are activated and favored [24]. The technological environment includes hardware (computers, smartphones, internet networks, servers...) and software (intranet, digital resources, information or educational software applications, information systems). "Entities (whether human or technological) do not have inherent properties, but acquire form, attributes, and abilities through their interpenetration. It is a relational ontology that presumes that social and material are inherently inseparable" [25]. Therefore, in this section we will study this 'interpenetration' and relationship between digital tools and the learners themselves. These tools directly or indirectly influence the ability of employees to access learning sources. After having identified the impact of technological capital on access to digital resources, particularly in the literature on digital learning tools, we have more specifically mobilized theories that specify this "interpenetration". The Technology Acceptance Model (TAM) [26] focuses on central factors of resource mobilization among NIEs based on perceived usefulness and usability. A second model [27] [28] gives importance to the notion of quality satisfaction of these tools associated with NIEs. In our opinion, these approaches allow the individual factors characterizing the learner's relationship with their technological environment to be taken into account. These approaches are therefore based on notions of intention to use them [29]. However, they take into little account the dimensions of the organizational context in which the tools are used by employees, for example in which context (itinerant or sedentary) the tool is used. The theoretical developments of the TAM as UTAUT (Unified Theory of Acceptance and Use of Technology) 
[30], however, emphasize the importance of variables such as social influence or enabling conditions [29].

Table 1. Synthesis of the literature review

\begin{tabular}{|c|c|c|}
\hline \multirow{2}{*}{$\begin{array}{l}\text { Professional } \\
\text { factors }\end{array}$} & $\begin{array}{l}\text { Routines and professions as well as } \\
\text { daily breaks with habits. }\end{array}$ & \multirow[t]{2}{*}{2} \\
\hline & Weak in exercise of the profession & \\
\hline \multirow[b]{2}{*}{$\begin{array}{l}\text { Managerial } \\
\text { factors }\end{array}$} & Social support & \multirow[b]{2}{*}{2} \\
\hline & $\begin{array}{l}\text { Corporate culture - learning } \\
\text { organization }\end{array}$ & \\
\hline \multirow{3}{*}{$\begin{array}{l}\text { Technological } \\
\text { factors }\end{array}$} & Perceived usefulness & \multirow{3}{*}{3} \\
\hline & Ease of use & \\
\hline & Perceived quality & \\
\hline
\end{tabular}

\section{Research design}

\subsection{A dual qualitative case study of a consulting firm and legal / health professionals}

Through inductive reasoning, we apply a qualitative protocol for data collection within the framework of two non-comparative case studies [31]. Each case study environment offered complementary elements to the other. Stake [32] insists specifically on the importance of the correspondence between the chosen case and the object of the research. This is why we propose to explore the subject through those "whose function is to create, disseminate or sell knowledge or intellectual services"'2: in other words, knowledge workers. The two organizational models studied are indeed characteristic of knowledge workers, 1) consultants and auditors in a consulting firm, which we call for the sake of confidentiality AuditFirm and 2) legal / health professionals in France. They allow us to study the phenomenon of informal learning within NIEs where it is most exacerbated. Indeed, in these environments there exists a powerful need for learning. Beyond being a fertile ground for our research, these two cases are also representative of new ways of working.

We triangulated the data collected [33], which allowed us to cross-check the information from 32 semistructured interviews, passive observation involving very regular informal exchanges, 200 pages of documents and the consultation of internal and external tools. The purpose of our research was only mentioned at the end of the interviews so as not to bias the answers. This in-depth protocol allowed us to identify the work context in order to better understand the factors that the interviewees referred to. A summary of the material collected is presented in the table below:
Table 2. Data collection

\begin{tabular}{|c|c|}
\hline $\begin{array}{c}\text { Data sources and } \\
\text { use in analysis }\end{array}$ & Details \\
\hline $\begin{array}{c}\text { 32 semi-structured } \\
\text { interviews }\end{array}$ & $\begin{array}{c}9 \text { auditors, 13 consultants, 2 } \\
\text { physiotherapists 3 pharmacists 1 } \\
\text { lawyer, 1 notary, 1 general } \\
\text { practitioner, 2 speech therapists } \\
(75 \text { minutes each on average) about } \\
\text { their work context, learning } \\
\text { behaviors, tools, usefulness and } \\
\text { perceived ease of use of digital tools }\end{array}$ \\
\hline 200 documents & $\begin{array}{c}14 \text { HR reports and newsletters, 5 } \\
\text { training plans, 19 AuditFirm } \\
\text { academy documents, 15 e-mails, } \\
\text { exchanges, 30 screenshots from tools } \\
\text { used, interfaces and digital } \\
\text { environments made available... }\end{array}$ \\
\hline $\begin{array}{c}\text { 15 days of observation and } \\
\text { Observation }\end{array}$ & $\begin{array}{c}\text { shadowing during informal moments } \\
\text { (e.g. phone calls, LinkedIn } \\
\text { exchanges, after-work events, e-mail } \\
\text { exchanges...), screenshots, journals, } \\
\text { recorded in the researcher's diary } \\
\text { with text, pictures and screenshots } \\
\text { for online observation. }\end{array}$ \\
\hline
\end{tabular}

\subsection{Data analysis}

We collected and organized qualitative data to provide an interpretation of the phenomenon (description, explanation and configuration) related to our research problem, in other words: why do knowledge workers self-learn within NIEs?

To answer this question, using Nvivo11 Pro $\odot$ we extracted verbatims from interviews that represented the causal nature of the uptake of informal learning within NIEs. We then included data from secondary sources (documents, shadowing and observation). Once this had been achieved, we conducted a thematic analysis using a dictionary of themes [33], which is presented in the table below. We identified level 1 (themes) the attributes, meaning specific factors from professional, organizational and technological dimensions, as well as the level 2 (subtopics) attributes that emerged from the field and converged precisely in each dimension. Building a dictionary of themes allowed us to classify common concepts and ideas using NVivo11 Pro $\mathbb{C}$. The coding was carried out gradually by identifying the recurring themes during the interviews. We operated from a clean slate, which through inductive reasoning allowed us to build up our literature review.

\footnotetext{
${ }^{2}$ https://web.archive.org/web/20121021084842/http://www.ftu.be: 80/documents/ep/EP-2008-17.pdf
} 
Table 3. Dictionary of theme headings

\begin{tabular}{|c|c|c|c|c|c|}
\hline QR & $\begin{array}{c}\text { Dimens } \\
\text { ions }\end{array}$ & $\begin{array}{c}\text { Level 1 } \\
\text { (themes) }\end{array}$ & $\begin{array}{c}\text { Level 2 } \\
\text { (subtopics) }\end{array}$ & $\begin{array}{c}\text { References } \\
\text { from } \\
\text { literature }\end{array}$ & $\begin{array}{c}\text { Defin Verba } \\
\text { ition }\end{array}$ \\
tim \\
\hline
\end{tabular}

We identified 3 categories of organizational factors; 5 professional factors, 3 managerial factors and 3 technological factors. As indicated, the average number of occurrences is 137 per sub-topic (level 2). The average number of verbatims associated with each subtopic within interviews is 4 (137/32 interviews). This means that each sub-topic was mentioned four times in each interview.

Table 4. Organizational factors promoting the use of informal learning within NIEs

\begin{tabular}{|c|c|c|c|}
\hline Level 1 & Level 2 & $\mathrm{~N}^{*}$ & $\mathrm{O} *$ \\
\hline \multirow{5}{*}{$\begin{array}{l}\text { Professional } \\
\text { factors }\end{array}$} & Pace and workload & \multirow{5}{*}{5} & 135 \\
\hline & Nature of the profession & & 223 \\
\hline & $\begin{array}{l}\text { Performance } \\
\text { requirements }\end{array}$ & & 118 \\
\hline & $\begin{array}{l}\text { Fragmentation of } \\
\text { physical spaces }\end{array}$ & & 70 \\
\hline & $\begin{array}{l}\text { Fragmentation of time } \\
\text { spaces }\end{array}$ & & 113 \\
\hline \multirow{3}{*}{$\begin{array}{l}\text { Managerial } \\
\text { factors }\end{array}$} & $\begin{array}{l}\text { Social supports } \\
\text { mechanisms }\end{array}$ & \multirow{3}{*}{3} & 190 \\
\hline & Corporate culture & & 165 \\
\hline & Organizational support & & 123 \\
\hline \multirow{3}{*}{$\begin{array}{l}\text { Technological } \\
\text { factors }\end{array}$} & Perceived usefulness & \multirow{3}{*}{3} & 126 \\
\hline & Ease of use & & 138 \\
\hline & Perceived quality & & 115 \\
\hline \multicolumn{2}{|c|}{$\begin{array}{ll}{ }^{*} & \text { Callout: } \\
- & \text { N: number } \\
- & \text { O: verbatim occurrences }\end{array}$} & & \\
\hline
\end{tabular}

\section{Results}

\subsection{Five professional factors}

Professional factors are defined as being directly related to the actual exercise of the profession.

4.1.1 Pace and workload. "Our worst enemy is time! [...] we always have strict deadlines to meet" (Iw1_Lawyer)."Laboratories are constantly sending out all the information on medicines!" (Iw24_Pharmacist).

One of the major common features among these knowledge workers, which was widely expressed during the interviews, is the pace and workload of professional life. The example of court appointments is interesting because it requires a quick preparation of the defense: "Yes, because in Paris in the role of court appointments there is something that appeals to me, I mean the police custodies, because when someone does something foolish and is arrested by the police and placed in custody, if they say 'I want a lawyer', I get called up immediately. [...] you don't have the time to prepare the defense. Often, in custody, you have just 20 minutes to organize yourself $[\ldots]$ and find the right strategy to get them out of trouble! [...] we are forced to train in situ." (Iw1_Lawyer). These are sectors that are experiencing rapid change, and which need to be adapted to quickly. The pace of work and the workload require a calculation of the utility/ease of access ratio of the source or learning resources characteristic of uptake of informal learning within NIEs.

4.1.2 Nature of the profession. When auditors and consultants presented their work context, they emphasized a very high work rate and a wide range of assignments. They regularly change clients, teams and assignments, which forces them to update their level of skills depending on the level expected at a specific point in time in order to successfully carry out each individual assignment. "When working with clients, we always need to know, [...] the structure of the client's organization to be able to carry out our assignments." (Iw3_Consutlant).

The work of consultants and auditors depends to a great extent on the missions they are assigned. "We can not necessarily target the right issues to follow the appropriate training beforehand, therefore we are trained on the job, due to time constraints and depending on the very specific nature of our assignments. [...]receiving technical training upstream on financial issues would be of little interest because we have no idea which assignment we're going to be allocated." (Iw28_Consultant). This need for consultants to rapidly update their knowledge is largely influenced by the specific nature of their profession. "Thirdly, I would talk about some technical and specific points that require a certain level of experience (consolidations, financial norms) that keep changing time and time again." (Iw9 Auditor).

Each new assignment requires an update of the required skills: "[...] if I don't know, then I Google it." (Iw14_Consultant).

Health and legal professionals are all the more affected by the need to tailor the way they adapt their knowledge to each case, that is to say, each patient or client. Pharmacists mention, for example, the issue of individual prescriptions: "We learn every day! The other day I had an oral suspension prescription for ****. [...] I had to do some research on how to fix the problem and it was pretty hard to find! As it was urgent, I spent half an hour sorting everything out!" (Iw24_Pharmacist).

It is for this reason that the uptake of informal learning within NIEs is essential because it provides access to a multitude of resources that maximize the potential for obtaining the necessary knowledge. Each individual needs to design their own learning programme.

4.1.3 Performance requirements "So as not to be bothered, in the morning I came in to sign the training 
course attendance sheet and then I left at the break, [...] I had no choice, because the partner does not want to, or cannot often wait, and is not interested in the fact that we are on a training course. Which made the training course completely useless because I could not follow it. However, I was registered as having followed the course and the attendance sheet was signed. [...] That way I did not receive an email asking why I had not attended the course from my supervisor or the performance manager. Except the 'performance manager' is the one who backs us for a bonus at the end of the year or a promotion... so you never know!" (Iw28_Auditor).

This verbatim illustrates the different schedules conditioning the day to day working life of knowledge workers. Consultants, for example, are subject to the schedule negotiated between the Associate and the client. They are therefore responsible for keeping to the deadlines and milestones negotiated with the client. The cost of the service provided is based on a precise schedule that must be respected. The consultant's workload may depend on unforeseen circumstances such as: excessively long delays in obtaining documents to be analyzed or the absences of certain team members. For auditors, there is the added complication of a legal calendar associated with financial regulations on 'closing accounts'. Finally, knowledge workers will multiply the number of schedules they have to juggle with according to the number of assignments they are working on. In other words, if a consultant or auditor is working on 3 missions simultaneously, the allocation of schedules will be multiplied by three, not to mention their personal schedules, such as holidays, which are not encouraged during the auditing "high season", for example. From an operational point of view, this translates into the fact that if a consultant has to go on a training course for three days, this time commitment will impact all stakeholders involved in the associated schedules, mentioned above, leading to delays. Yet a consultant is better off not upsetting their line managers by 'slowing down' the project because of training days, even if the course is quite interesting and that the desire to participate is commendable, because in the end it is the line managers who will decide on the quality of performance appraisals that influence whether consultants are promoted or not. Thus, knowledge workers will favor the uptake of informal learning within NIEs because of the agility and efficiency they offer in being adaptable to hectic schedules. Those working in the professions are also forced, by various schedules and imposed deadlines, to achieve expected results. We give the example of health professionals who must find the right remedy immediately, especially when their patients are suffering. Notaries depend on external organizations and imposed deadlines, notably from banking institutions. Pharmacists and doctors are also affected by an "on-call schedule set by the local police force." (Iw22_Pharmacist). This on-call schedule requires doctors and pharmacists to be on 24-hour emergency call over a set period of time. Lawyers also mention being subject to the schedule of their cases and that of stakeholders.

4.1.4 The fragmentation of physical spaces. "We travel around a lot! For example, I have worked for several clients in one day. You'd better not count your hours working or travelling [...] This mobility is often supported by tools enabling us to work on projects from a distance. [...] about telework, it's something that is becoming common thanks to the VPN and Smartphones provided by the firm." (Iw28_Consutlant). The consultants began by reminding us that the trips were daily and part-and- parcel of the job. One of the inherent characteristics of these professions is flexibility, working in different teams simultaneously for a long list of clients. Another characteristic of the consulting profession is mobility going from one assignment to another. For health or legal professionals, this means trips to clients, patients, hospitals or organizations such as courts or tribunals. In the context of these business trips, and more generally with regards to switching assignments, contacts and work tools require individuals to be located almost permanently in a "learning zone" as opposed to a "comfort zone". These changes require constant updating and adaptation that promotes the use of digital informal learning.

4.1.5 The fragmentation of time spaces. Knowledge workers also have a duty to be "available" (Iw5_Medecin). Their professions have a cyclical workload regularly involving unforeseen events. This is why the frontier between professional and personal time becomes porous, because work is done during the time usually spent on personal life. "An auditor has a lot of work [...] You must always be prepared to meet the needs of the client, as far as is possible of course!" (Iw9_Auditor). Other consultants mention the stress involved in being constantly busy all day long, and not being able to have the necessary time to devote to development and learning. "I participate in training courses, almost always during my personal time." (Iw7_Auditor). Some health professionals mention their obligation to be available to patients who are sometimes in distress. "Sometimes there are patients, who are friends, who ask me questions [...] You are constantly asked things. For example, when friends are sick, they ask me to open the pharmacy to look for medicines." (Iw24_Pharmacist). 


\subsection{Three managerial factors}

Managerial factors are the set of factors intrinsic to an organization favoring the uptake of informal learning within NIEs.

4.2.1 Social support mechanisms. Social support mechanisms influence the use of informal learning within NIEs. This support is particularly noticeable through the relationship with the manager, whether they be prescriber or advisor.

The manager as prescriber."... I find that they don't necessarily have the answer, because they are too involved in the managerial function, and as a result, they are too busy with hierarchical or administrative issues and stuff like that. That's why, I find that in the end they do not necessarily have more expertise than me in an area. [...] Are consultants able to know what they need to learn? This is the question that needs to be asked. But is he [the manager] more able than you to know what you need? I'm not always sure about that." (Iw3_Consultant). The manager is traditionally the expert, the one who, within their team knows the job. The dialogue is sometimes difficult because the job of manager is very different from that of consultants as it involves a predominantly commercial dimension: "the manager goes to see the client just for important things." (Iw14_Consultant).

Managers evaluate each auditor three times a year along with other staff members of the same rank, and according to the evaluations carried out at the end of each assignment. Promotion to a new rank will increase "confidence [...] it is very motivating for the future." (Iw12_Auditor). On the other hand, the manager can also offer incentives as part of the annual appraisal interviews, notably by dissuading the consultant to talk about their weaknesses, so that they are not recorded in the appraisal report, and encouraging them to go through more discreet learning channels such as informal learning through NIEs: "My impression is that they will quickly put you into a category, sort of, she's not up to it! I prefer not to be judged in fact, it's too risky especially for our appraisals." (Iw3 Consultant).

The 'manager as prescriber' therefore also contributes to promoting the uptake of informal learning within NIEs, which is more adapted to the expectations of learners than traditional learning situations. However, AuditFirm is in fact committed to providing high quality training courses run by specialists. The high level of investment in training is also visible via the technical support (e-Learning platforms, training rooms, running of seminars in France or internationally, combining training with more relaxed activities, etc.). "The training is very dense, run by leading practitioners, lawyers and financial consultants, who for many have participated in the financial turnaround of major companies, but we have unfortunately other things to be getting on with. We have our managers waiting for their documents before the end of the day, while our training courses never finish before $6.00 \mathrm{pm}$. [...]. We must answer urgent emails, otherwise we hold up all the teams we work for, we are left voicemails, it's unbearable." (Iw27 Auditor). Health professionals may also experience difficulties with travel to training courses, which naturally forces them to use digital informal learning methods: "I worked for an employer who didn't want us to do any training, in spite of the advice of the College of Pharmacists [...] my employer told me, 'I refuse to send you on a training course!'. I replied: 'For me, training is important, so I will train in my personal time'. He ended up accepting that I follow one elearning training course every year." (Iw24 Pharmacist).

The manager as advisor. Firstly, concerning their relationship with team members, managers can point staff to reliable and interesting resources and recommend sources of knowledge. "There are people I ask, who were directly recommended to me by my boss [...]: 'Call such-and- such a person, they will help you!'" (Iw27_Auditor). The manager can also guide their teams to useful resources, including "collaboration platforms, social networks, MOOCs, e-Learning material, e-books, online publications, online articles." (Iw4_Consutlant), which means their team knows they can be trusted regarding resources to consult for learning purposes, people to contact, articles, books and useful websites. Managers can implement projects in collaboration with experts to provide opportunities for the transmission of skills.

4.2.2 Corporate culture. The corporate culture of knowledge workers is focused on self-esteem and performance. It aims to develop the social recognition of peers, managers, clients or patients. It has two complementary objectives: firstly, to enable the knowledge worker to move up within the structure; secondly, to develop one's reputation to the benefit of the business. This quest for performance is visible "physically" through internal and external communications centered on performance. Professionals are always looking for ways to improve. "Proximity and getting on with managers is fundamental regardless of the quality of their work. [...] I think it influenced the fact that I've been put on interesting assignments. It's very political!'” (Iw16_Consultant). The culture at AuditFirm recommends teams work autonomously, especially through managers encouraging their teams to look first for answers to their questions before soliciting them: "One of the first reflexes is to Google the right answer if necessary: I can say that every day when junior members ask me questions, I ask them: 'did you Google 
it?" (Iw14 Consultant). A corporate culture focused on performance, poses difficult and risky challenges, like having the life of patients in their hands. But this challenge forces knowledge workers to develop their skills and master their learning.

4.2.3 Organizational support. Why do we talk about the "Great Training Robbery"? Knowledge workers mentioned a certain lack of understanding from HR departments and authorities on learning applications in practice, which they sometimes see as "disconnected from [their] reality." (Iw16_Auditor). "For the last 2 years I've been asking for crisis management training, so my manager told me: 'it's legitimate, I know you need it, but the problem is that it's reserved for senior managers'." (Iw3 Consutlant). "[...] I've been waiting to get a training certificate for a year and a half." (Iw3_Consultant). They finish up by asking themselves "Apart from having legal protection I've no idea what their use is." (Iw26_Physiotherapist).

They also criticize infantilizing situations with sign-in sheets and reminders, which they do not see as appropriate to their level of responsibility: "I think they like the face-to-face approach, because we have a signin sheet for each training session and it's a way of controlling us. [...] normally each one of us is able to self-train and identify our weak areas without having to sign-in." (Iw3_Consultant).

Between the steps to be taken and HR policies, they become lost, and this is how these same learners move towards informal learning within NIEs. "[...] I don't find the courses sufficiently challenging for my level, [...] I train myself on the Internet, with others or with outside companies." (Iw3_Consultant). Between the feeling that training courses are being squeezed in, that they don't suit everybody and that mandatory elearning courses are set up just to please clients or the authorities, the actual meaning of training has been lost and leads to deviant behaviors: "[...]AuditFirm must be able to prove that we are up to date on new legislations [...] Every year, there is this e-learning to do. [...] to be honest, we were doing it all together and we shared all the answers, the HR department just wants to be able to prove that we have done the training, and that's it! [...] So, that didn't really concern us." (Iw17_Auditor). The uptake of informal learning within NIEs involves approaches that are adapted to knowledge workers' way of working, their organization and their sustained and demanding work pace. These are approaches that emanate from within a constrained environment. As part of the policy to develop employees' skills, AuditFirm, for example, spends about 25 million euros per year on training. AuditFirm opens up access to its content (previous assignment material, training material, news) on the company intranet and offers access to a choice of rich and varied training courses. These courses are the opportunity to strengthen one's basic knowledge and work on problems encountered in business. It gives individuals the opportunity to ask any questions and to learn the essential points required to do the job properly as auditors (accounting standards, methodology, technical points, specific IT tools ...). But, "a training course is only really finished once you master the technique by putting it into practice in your everyday work [...] faced with specific contexts." (Iw23_Consultant). Training is run on specific dates, which means it is not always at the right time in the right place for everyone. We observe an investment by the company in the training of auditors, but on the other hand we identify learners who are experiencing difficulties because they are overworked and working simultaneously on several assignments.

In this way, auditors spontaneously adopt the uptake of informal learning within NIEs, i.e. the use of simple online knowledge acquisition solutions and the creation of learning and collaboration networks. These networks are not valued in HR. Knowledge workers mention "the lack of time and support allocated to their approach, which is misunderstood and not recognized by managers or the organization." (Iw13 Consutlant).

\subsection{Three technological factors}

Technological factors are defined by learners as "facilitators and as determining the level of learning" (Iw16_Consultant). Two families of tools were mentioned; 1) communication tools, seen as vectors, and 2) the content, intranet and Information Systems, identified as a pool of wide-ranging and varied information. The proliferation and densification of tools that are external to the organization have transformed professionals' uptake of informal learning within NIEs.

4.3.1. Perceived usefulness. During our empirical analysis, we realized that there is now a phenomenon of dependence on technology, (including information and communication technology) in employee learning. Reference is made here to a problem of distance between members of the community. Communication tools are more integrated in informal collective and collaborative practices. They can be asynchronous (mails) or instantaneous (Skype) and are considered to be essential by learners for access to the necessary information. "These are our main means of communication; we can ask our questions directly to people who are known to have the answer without wasting time. It also allows us to work remotely simultaneously." (Iw17_Auditor). New collaborative workspaces can also become tools for daily work and knowledge sharing. "We also sometimes put documents on Google Drive or in Drop Box, because it's simple and 
we know that we can view information on all systems." (Iw29_Orthophonist).

4.3.2. Ease of use. In these new learning behaviors, a sense of self-efficacy and expectations of self-efficacy for future learning exists. We identify here the dimensions of self-efficacy [16]. Individuals will take up a learning behavior in which they feel effective, whether rightly or wrongly. Today, besides judgments on quality and use, the effectiveness of learning resources and content is evaluated, that is to say the speed at which the right knowledge is acquired at the right time and in the right place. They are ready to bypass access restrictions or locked sites and to access for long periods of time external sources that are fast and easy to use, thus ignoring regulations requiring authorization by their firm to access external sites. In this sense, if no one in-house is able to transmit the required knowledge, auditors and consultants do not hesitate to integrate an external network, whether existing or being built. "I find the e-learning well done, appropriate for our activities, but they do take up our whole screen, so we don't have access for example to the internet to complete the terms, and especially we don't know when it will end. [...] we can't always do that and sometimes it is a waste of time because we need to move ahead quickly: for example for 45 minutes of eLearning, we can waste 40 minutes, yet we have a mountain of work waiting for us." (Iw_15, Consultant).

Today, digital tools are taking off because they are simple to use and dense in terms of proposed solutions. They correspond to a specific and immediate need.

4.3.3. Perceived quality. "They are exceptional sites. I'll look for something on the website of the National Assembly for example [...] The only source that I can blindly trust is the 3 databases. There I know that what I find is serious stuff." (Iw1_Lawyer).

Even though the evaluation of communication tools is positive, they are much less so regarding information systems, the intranet, training material or information media and databases made available to employees. Indeed, some individuals feel that communication tools do not necessarily promote learning. It is undeniable that the high quality of content is essential. And the learners interviewed admitted naturally that there is no shortage of content at AuditFirm, as regards the intranet. "We have access to a great deal of information, including our predecessors' assignment reports, so we have to go and find answers to our questions, which is part of what is expected of us by our superiors [...]" (Iw2_Consultant). But the difficulty is with this "information overload [...] between newsletters, the internet, our intranet, etc., we spend a lot of time finding the info in the right place and making sure that it is accurate." (Iw12_Auditor). As far as misuse is concerned, we are also told that the sources of information are many and paperless. Some even refer to open source training tools: "I'm going to find a lot of my information on the Internet, including pro documents, share slides, all the tutorials or news sites, etc.[..]" (Iw22_Consultant). Access to the firm's rich resources within NIEs (assignment reports, etc.) needs to be simplified to encourage their use. In sum, these factors help us to better understand new practices of learning. We will also discuss the individual learning factors, as well as the role of the line manager and that of the company.

\section{Discussion}

\subsection{Theoretical contributions}

The research on informal learning through NIEs is based on the unstructured field of research in informal learning and digital learning. In this context of nonunified theory [34], we propose a new framework of analysis and discussion. Our theoretical framework is positioned in the field of informal learning and aims to update in the current context the factors that encourage the uptake of informal learning within NIEs. "While much is known about these pervasive forms of adult learning, much remains to be learned." [20]. Several directions for future research exist: " future work is needed to continue exploring the role of context [...] influence the learning process." [35]. To date, the existing literature has only explored or understood part of the current informal learning of knowledge workers. Professional factors are one aspect of a category that, to our knowledge, is not yet directly related to the uptake of informal learning within NIEs but generalized to all learning situations [36]. Indeed, within this research, professional factors such as the uptake of informal learning within NIEs were widely represented. Some factors lack theoretical foundations. The pace and the workload, the commitment to achieving results, the fragmentation of spaces and time spaces require a wealth of resources and an agility in the learning offered by digital solutions. Technological factors also lead to the mobilization of NIEs, in a different way and according to the resources used. At least, informal learning studies have been conducted in many professional contexts [37] but studies of knowledge workers and moreover within NIEs are rare [38]. To date, we have not been able to identify studies showing the specificities of knowledge workers.

\subsection{Managerial contributions}

"Informal workplace learning takes an increasingly focal role in human resource development practice and research, as it contributes to organizations' adaptability and competitiveness." [19] 
For several years, the development of NIEs has made it possible to give new practices to traditional informal learning. After an expansion of formalized learning moments and spaces within organizations, this recourse to more informal ways thus appears as the expression of a return to self-learning.

For this reason, it is important to understand why employees take up informal learning within NIEs, $(61 \%$ of professionals in France), given that $90 \%$ (more than $\$ 100$ billion) of training expenses are lost in the USA. The company as a place to capitalize on knowledge is increasingly challenged by professional communities created by the use of social networking tools, among others. The company is no longer the only type of structure where complex projects are undertaken (for instance, Wikipedia, social networks or open-source software solutions). New ways of working that are very specific to consulting firms (intrapreneurship) and legal/health professionals (entrepreneurship) have supported informal learning within NIEs. Naturally in the hands of learners, but neither recognized nor measured by organizations, informal learning within NIEs should be accompanied by organizations, including via IS, HR services and managers. Companies remain influential in structuring people's work and in managing complex projects requiring different skills and management. We offer a report from the field in terms of learning, ownership and knowledge mobilization. In order to weave an effective link between the HR departments and the teams in the field, we first suggest identifying the uptake of informal learning within NIEs and the factors behind these through a survey and a series of interviews. It is thus possible to map the practices and factors put forward. Informal learning within NIEs is conscious, selfdirected and self-sustaining. Its effectiveness depends on the potential offered by the NIE. However, in order to be entrenched over time this learning must be contextualized. The HR department must then act as a facilitator in order to optimize employee skill development paths and propose the following areas of facilitation: develop a list of accessible resources and access to flexible and content-rich micro-learning modules; give employees time to develop business monitoring activities or communities of learners; open existing digital devices and not focus on measuring the completion rate; integrate the uptake of informal learning within NIEs into the skills development plan of employees.

\subsection{Limitations and future research}

One of the identified limitations concerns the category of interviewees. In order to bring out as much data as possible on the factors influencing the uptake of informal learning within NIEs we selected a situation where the phenomenon already existed. For this reason, this research should be pursued by a search for more general results in more diversified contexts and finally by drilling down deeper into the role of the manager.

To conclude, theses organizational factors promoting the uptake of informal learning within NIEs offer many opportunities of future research. In a future research, we could complete this list of factors with those generated by the context imposed by the current health crisis and identify the factors promoting the uptake of informal and self-learning within remote work.

\section{References}

[1] M. Beer, M. Finnstrom, and D. Schrader, The Great Training Robbery. In, 2016, pp. working paper.

[2] Q. Cao, D.R. Jones, and H. Sheng, H., "Contained nomadic information environments: Technology, organization, and environment influences on adoption of hospital RFID patient tracking" Information \& Management, 51(2), 2014, pp. 225-239.

[3] V.J. Marsick, and K.E. Watkins, "Informal and Incidental Learning", New Directions for Adult and Continuing Education,, 2001, pp. 25-34.

[4] K. Lyytinen, and Y. Yoo, "The next wave of nomadic computing: A research agenda for information systems research", Information Systems Research, 134, 2002, pp. 377-388.

[5] Carré, P., Moisan, A., and Poisson, D., L'autoformation. Perspectives de recherche, Presses universitaires de France, Paris, 2010.

[6] Le Ny, J. F., Le conditionnement et l'apprentissage, PUF, Le Psychologue, Presses Universitaires de France, Paris, 1992.

[7] A.P Else Ouweneel, T.W. Taris, S.J. van Zolingen, and P.J. Schreurs, "How task characteristics and social support relate to managerial learning: empirical evidence from Dutch home care" The Journal of psychology, 143(1), 2009, pp.28-44.

[8] Carré, P., and Charbonnier, O., Les apprentissages professionnels informels, Editions L'Harmattan, Paris, 2003.

[9] Mintzberg, H., Mintzberg on management: Inside our strange world of organizations. Hungry Minds Inc,U.S. New York, 1989.

[10] J. Chevrier, G. Fortin and R. Leblanc, and M. Théberge, "Problématique de la nature du style d'apprentissage", Éducation et francophonie, 28(1), 2000, pp. 3-19.

[11] E. Bernardin, " Corporate e-learning: perspective andragogique et technologies de la formation », 2005, (No. hal-00796684).

[12] Dejoux C., " Rh pour le manager », Fonctions RH : Politiques, métiers et outils des ressources humaines, dir. Thévenet, Dejoux, Marbot et Bender, Pearson Education, Paris, 2007.

[13] S.I. Tannenbaum R.L Beard, L.A McNall, and E. Salas, "Informal learning and development in organizations" Learning, training, and development in 
organizations, 2010, pp. 303-332.

[14] T.A Judge, and R.F. Piccolo, "Transformational and transactional leadership: a meta-analytic test of their relative validity", Journal of applied psychology, 89(5), 2004, pp.755.

[15] B.M Bass, and R.E. Riggio, Transformational leadership. Psychology Press, 2006.

[16] Bandura, A., and Walters, R. H., Social learning theory (Vol. 1). Englewood Cliffs, NJ: Prentice-hall.1977.

[17] M. Callanan, C. Cervantes, and M. Loomis, "Informal learning". Wiley Interdisciplinary Reviews: Cognitive Science, 2(6), 2011, pp. 646-655.

[18] R.W. Duncan, "Organizational learning: Implications for organizational design” Research in Organizational Behaviour, 1, 1979, pp. 75-123.

[19] D. Froehlich, M. Segers, and P. Van den Bossche, "Informal workplace learning in Austrian banks: The influence of learning approach, leadership style, and organizational learning culture on managers' learning outcomes." Human resource development quarterly, 25(1), 2014, pp. 29-57.

[20] V.J Marsick, M. Volpe, and K.E. Watkins, "Theory and practice of informal learning in the knowledge era", Advances in Developing Human Resources, 1(3), 1999, pp. 80-95.

[21] R. Moilanen,"Diagnostic tools for learning organizations", The learning organization, 8(1), 2001, pp. 6- 20.

[22] Senge, P., The fifth discipline: The art and practice of learning organizations, New York: Doubleday, 1990.

[23] W.J. Orlikowski, "Sociomaterial practices: Exploring technology at work", Organization studies, 28(9), 2007, pp. 1435-1448.

[24] T. Wallner, and M. Menrad, "High performance work systems as an enabling structure for self-organized learning processes.", In ICL, 2012 15th International Conference on Interactive Collaborative Learning, IEEE, 2012, pp. 1-6,

[25] W.J Orlikowski, and S.V Scott, "10 sociomateriality: challenging the separation of technology, work and organization", Academy of Management Annals, 2(1), 2008, pp. 433-474.

[26] F.D. Davis, "Perceived usefulness, perceived ease of use, and user acceptance of information technology", MIS Quarterly, vol. 13, 3, 1989, pp. 319-340.

[27] W.H. Delone and E.R McLean, "Information systems success: the quest for the dependent variable", Information Systems Research, vol. 3, 1, 1992, pp. 6095.

[28] W.H Delone and E.R McLean, "The DeLone and McLean model of information systems success: A tenyear update", Journal of Management Information Systems, vol. 19, 4, 2003, pp. 9-30.

[29] Baudoin, E., Facteurs de suivi et apprentissages individuels des salariés dans des parcours e-learning: quatre études de cas chez un constructeur automobile (Doctoral dissertation, Université Paris-Dauphine), Paris, 2010.

[30] V. Venkatesh et al.,"User acceptance of information technology: toward a unified view", MIS Quarterly, vol. 27, 3, 2003, pp. 425-478.

[31] Yin, R. K., Case Study Research: Design and Methods (5th ed.): Sage Publications, Thousand Oaks, 2014.

[32] Stake R.E., "Case Studies", in N.K. Denzin et Y.S. Lincoln (Eds.), Strategies of Qualitative Inquiry, Sage Publications, vol. 2, chap. 4, pp. 86-109, California, 1994.

[33] Miles, M. B., and Huberman, A., M., \& Saldana, J., Qualitative data analysis: A methods sourcebook, 3., Thousand Oaks, CA, 2014.

[34] S. Jeong, S.J. Han, J. Lee, S. Sunalai, and S.W. Yoon, "Integrative literature review on informal learning: antecedents, conceptualizations, and future directions", Human Resource Development Review, 17(2), 2018, pp. $128-152$.

[35] C.G. Myers, "Coactive vicarious learning: Toward a relational theory of vicarious learning in organizations", Academy of Management Review, 43, 2018, pp. 610634.

[36] J.E. Mathieu, S.I Tannenbaum, and E. Salas, "Influences of individual and situational characteristics on measures of training effectiveness.", Academy of management journal, 35(4), 1992, pp. 828-847.

[37] R.A Bjork, J. Dunlosky, and N. Kornell, "Self- regulated learning: Beliefs, techniques, and illusions", Annual review of psychology, 64, 2013, pp. 417-444.

[38] C. Campion-Smith, H. Smith, P. White, E. Baker, R. Baker, and I. Holloway, "Learners' experience of continuing medical education events: a qualitative study of GP principals in Dorset" Br J Gen Pract, 48(434), 1998, pp. 1590-1593. 